Journal of Mechanical Engineering and Sciences

ISSN (Print): 2289-4659; e-ISSN: 2231-8380

Volume 12, Issue 4, pp. 4231-4242, December 2018

(C) Universiti Malaysia Pahang, Malaysia

DOI: https://doi.org/10.15282/jmes.12.4.2018.18.0364

\title{
Response prediction of reverse engineered freeform surface by design of experiments
}

\section{G. Sreeram Reddy ${ }^{1}$, V.V. Satyanarayana ${ }^{2}$, M. Manzoor Hussian ${ }^{3}$ and J. Jagadesh Kumar ${ }^{4}$}

Dept. of Mechanical Engineering, Vidya Jyothi Institute of Technology, Hyderabad, India $1,2,4$

Mobile: +91 - 9440444475;

Email: sreeramgundeti@gmail.com

Dept. of Mechanical Engineering, JNTUH College of Engineering,

Hyderabad, India ${ }^{3}$

\begin{abstract}
Reverse engineering is a new technique employed in product design wherein original drawings or pertinent technical data are not available. Reverse engineering technology acquires the conceptual designs from the existing products and consequently creates digital product models. In the product design these digital products are employed with optimization principles. The investigation in this paper encompasses 3-D reconstruction of products by the reverse engineering technique and consequently identifying the deviations between the original product and the reverse engineered model. Design of experiments is a systematic study in the consideration of the governing parameters and there by arriving at the optimization stage. In this investigation response surface methodology method is employed by taking the input parameters viz noise level, smoothing level and triangle count \%; and there by identified the responses namely deviation and curvature deviation occurred from the existing physical model. The deviations and curvature deviations are in the range 0.0266 to $0.0621 \mathrm{~mm}$ and 0.543 $(54.3 \%)$ to $0.645(64.5 \%)$ respectively which indicate that the reverse engineered freeform surface is not exhibiting significant difference when compared to the original CAD model. Response surface contours are constructed for determining the optimum process conditions.
\end{abstract}

Keywords: Reverse Engineering; Response Surface Methodology (RSM); Deviation; Coordinate Measuring Machine (CMM); Analysis of Variance (ANOVA).

\section{INTRODUCTION}

Originally Reverse engineering was defined as "the process of developing a set of specifications for a complex hardware system by an orderly examination of specimens of that system" [1]. Chikofsky and Cross [2] defined reverse engineering as "the process of analysing a subject system to identify the systems components and their relationships, and to create representations of the system in another form or at a higher level of abstraction'. In mechanical design, reverse engineering can be defined as the process that "initiates the redesign process wherein a product is predicted, observed, disassembled, analysed, tested, 'experienced', and documented in terms of its functionality, form, 
physical principles, manufacturability, and assemblability' [3]. Reverse engineering and shape reconstruction play an important role in design and manufacturing through the increased use of shape acquisition and processing technologies in the product development process [4]. Laser scanning is a known non-contact measuring and scanning technique that is commonly used in reverse engineering processes and used for capturing freeform surfaces. The accuracy of models obtained by reverse engineering, identification of critical parameters and algorithms will affect the geometry and dimensional accuracy [5]. A benchmark for evaluation of mesh reconstruction techniques shows that reliable topological and geometrical guarantees are raised by sampling strategy, density, noise, outliers and sharp features [4]. The scanning process by Non-contact methods in the reverse engineering process influence the physical properties including the surface integrity greatly [6,7]. The morphology and local geometry of the captured surfaces have not been considered in most of the studies, and hence error compensation is offended [8, 9]. The final accuracy level of reverse engineered surfaces depends on number of input points of point cloud data, number of triangles in polygon model and noise reduction [9]. The accuracy of the reconstructed surface is improved by minimizing the noise of the input data [10]. In reverse engineering process existing part or surface is digitized with CMM or laser scanner to get required point cloud, which is triangulated in to mesh, and consequently converted, to CAD model. Reverse engineering is widely used in numerous applications, such as manufacturing, industrial design, jewellery design and reproduction. Surface accuracy is important factor in reverse engineering process and to know its deviations in advance, it is economical to employ statistical methods to predict deviations as a function of process conditions. A low sampling results in poor reconstruction where as large samples contain noisy data with high computation time [11]. Taguchi methods are applied for the reverse engineering methods and the effect of parameters on memory deviation; time deviation and curvature deviation are studied [12]. RSM technique is applied on free form surface construction and developed the predictive models for evaluating the final accuracy $[5,13]$. Design of experiments is an effective tool used for suggesting the effect of process parameters, quantum of variation, process output and its optimal values etc $[14,15,16]$.

In the current investigation, reverse engineered freeform surface is developed for a component having curvature in all the three dimensions, by initially scanning the component employing non-contact method. The reverse engineered model developed is compared to the CAD model of the component. The deviations and curvature deviations are evaluated from this comparison using Response Surface Methodology technique availing the parameters viz. noise level reduction, triangle count $\%$ and smoothing levels. The central composite design method is undertaken for the matrix during experimentation.

\section{METHODS AND MATERIALS}

\section{Surface Reconstruction}

A Computer Numerical Control milling machine is employed for machining a 3D part which has free form surfaces with sharp edges and capable to acquire point cloud data with the aid of portable laser scan. The scanning is carried out at a rate of 19,200 points/sec with an accuracy of 35 microns. Acquired point cloud data is cleaned through the available tools viz. delete outliers and select disconnected components. Figure 1 shows the selected part, acquisition laser scan setup and aligned point cloud data. 


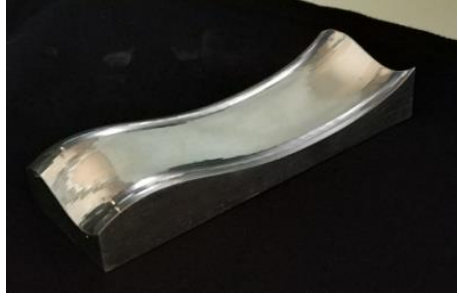

Selected part

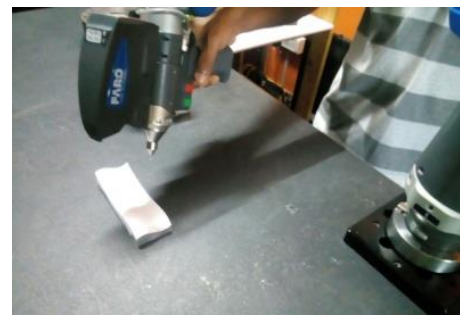

Scan setup

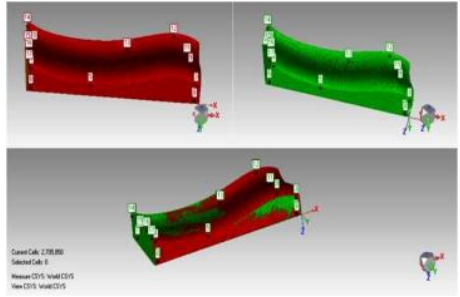

Point cloud data

Figure 1. Scanning process

\section{Measurement of Deviation}

The deviation is measured by comparing reference and the test model curvature maps [19] and evaluation is done accordingly. However, in this investigation Curve-D algorithm is used to compare the CAD model reference image and the reverse engineered model [20] at various sample sizes.

\section{Design of Experiments}

RSM is a statistical and mathematical method that is useful for modeling and analyzing engineering problems. In this technique, the main objective is to optimize the response surface that is influenced by various process parameters. RSM also quantifies the relationship between the controllable input parameters and the obtained response surfaces $[14,15]$.

The acquired point cloud data is huge and hence sampling method is adopted for detailed study. Investigation is carried out from a small sample of $20 \%$ of the points and extended further to study the whole population points in the incremental steps of $20 \%$.

The deviation and curvature deviation between the reverse engineered model and CAD model are taken as the responses for thorough investigation. The offset distance between predefined points on actual surface and corresponding points on reverse engineered model is measured by contact based CMM. Root mean square (RMS) values of measured points are taken to calculate deviation. While the curvature deviation is evaluated by comparing Gaussian curvature of reverse engineered model with the original CAD model as illustrated in Figure 2.

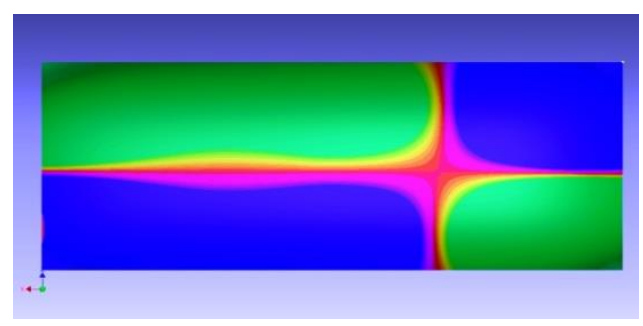

Original CAD model



Reverse engineered model

Figure 2. Curvature Analysis

Many statistical techniques are available for the study however response surface methodology (RSM) technique is chosen due to its inherent strengths like easy measure of the effects of the parameters and their interactions. In this article three parameters are chosen for their effect on the deviation and curvature deviation. Trial runs are conducted and the range of parameters along with their levels are fixed (Table.1). 
Table 1. Process Parameters

\begin{tabular}{clcccccc}
\hline S No & \multicolumn{1}{c}{ Parameters } & Notation & -2 & -1 & 0 & 1 & 2 \\
\hline $\mathbf{1}$ & Noise reduction level & A & 0 & 1 & 2 & 3 & 4 \\
$\mathbf{2}$ & Triangle count (\%) & B & 20 & 40 & 60 & 80 & 100 \\
$\mathbf{3}$ & Smoothing levels & C & 0 & 2 & 4 & 6 & 8 \\
\hline
\end{tabular}

The experiments are contemplated to conduct according to central composite design (CCD) of the RSM and the response polynomial is in the form;

$$
\mathrm{Y}=\mathrm{b}_{0}+\mathrm{b}_{1} \mathrm{x}_{1}+\mathrm{b}_{2} \mathrm{x}_{2}+\mathrm{b}_{3} \mathrm{x}_{3}+\mathrm{b}_{4} \mathrm{x}_{1}^{2}+\mathrm{b}_{5} \mathrm{x}_{2}^{2}+\mathrm{b}_{6} \mathrm{x}_{3}^{2}+\mathrm{b}_{1} \mathrm{x}_{1} \mathrm{x}_{2}+\mathrm{b}_{8} \mathrm{x}_{2} \mathrm{x}_{3}+\mathrm{b}_{9} \mathrm{x}_{1} \mathrm{x}_{3}
$$

The coefficients are computed by least square method and analysis of variance (ANOVA) is performed by Yates algorithm $[14,15,16]$ and the regression equations are developed $[17,18]$. The analysis is conducted for $95 \%$ confidence level and $5 \%$ level of significance.

\section{RESULTS AND ANALYSIS}

All the experiments are conducted randomly to avoid the bias and the responses are observed. The measured responses for various sample sizes are given in Table. 2 and Table 3.

Table 2. Results for deviation

\begin{tabular}{ccccccccc}
\hline \multicolumn{6}{c}{ Parameters } & \multicolumn{5}{c}{ Deviation(mm) } \\
\hline Run & A & B & C & $20 \%$ & $40 \%$ & $60 \%$ & $80 \%$ & $100 \%$ \\
s & & & & sample & sample & sample & sample & sample \\
1 & -1 & -1 & 1 & 0.0513 & 0.036 & 0.0316 & 0.0295 & 0.0281 \\
2 & 1 & 1 & 1 & 0.037 & 0.0305 & 0.0286 & 0.0275 & 0.0268 \\
3 & 0 & -2 & 0 & 0.0621 & 0.0404 & 0.0347 & 0.0322 & 0.0302 \\
4 & -1 & -1 & - & 0.0328 & 0.0298 & 0.0281 & 0.0268 & 0.027 \\
& & & 1 & & & & & \\
5 & 0 & 0 & 0 & 0.0344 & 0.0294 & 0.0284 & 0.0274 & 0.0271 \\
6 & 1 & -1 & - & 0.0329 & 0.0291 & 0.0273 & 0.0276 & 0.0268 \\
& & & 1 & & & & & \\
7 & 0 & 0 & 0 & 0.0344 & 0.0294 & 0.0284 & 0.0274 & 0.0271 \\
8 & -1 & 1 & - & 0.0292 & 0.0286 & 0.0272 & 0.0267 & 0.0264 \\
& & & 1 & & & & & \\
9 & 1 & 1 & - & 0.0299 & 0.0278 & 0.027 & 0.0266 & 0.0266 \\
& & & 1 & & & & & \\
10 & 0 & 0 & 0 & 0.033 & 0.0294 & 0.0284 & 0.0274 & 0.0271 \\
11 & 1 & -1 & 1 & 0.0494 & 0.0357 & 0.0316 & 0.0296 & 0.0282 \\
12 & 0 & 0 & 0 & 0.0344 & 0.0294 & 0.0284 & 0.0274 & 0.0271 \\
13 & 0 & 0 & 0 & 0.0344 & 0.0294 & 0.0284 & 0.0274 & 0.0271 \\
14 & 0 & 0 & 2 & 0.0461 & 0.0341 & 0.0309 & 0.029 & 0.0276 \\
15 & 2 & 0 & 0 & 0.0356 & 0.0304 & 0.0289 & 0.0279 & 0.0273 \\
16 & 0 & 0 & 0 & 0.0344 & 0.0294 & 0.0284 & 0.0274 & 0.0271 \\
17 & 0 & 0 & - & 0.0343 & 0.03 & 0.0295 & 0.0283 & 0.0284 \\
18 & -1 & 1 & 1 & 0.0365 & 0.0302 & 0.0286 & 0.0272 & 0.0267 \\
\hline
\end{tabular}




\begin{tabular}{ccccccccc}
\hline 19 & 0 & 2 & 0 & 0.0315 & 0.028 & 0.0272 & 0.0268 & 0.0266 \\
20 & -2 & 0 & 0 & 0.0355 & 0.0291 & 0.0276 & 0.027 & 0.0266 \\
\hline
\end{tabular}

Table 3. Results for curvature deviation

\begin{tabular}{ccccccccc}
\hline \multicolumn{3}{c}{ Parameter } & \multicolumn{5}{c}{ Curvature Deviation } \\
\hline Sun & A & B & C & $20 \%$ & $40 \%$ & $60 \%$ & $80 \%$ & $100 \%$ \\
s & & & & sample & sample & sample & sample & sample \\
1 & -1 & -1 & 1 & 0.615 & 0.62 & 0.551 & 0.589 & 0.614 \\
2 & 1 & 1 & 1 & 0.615 & 0.626 & 0.559 & 0.559 & 0.612 \\
3 & 0 & -2 & 0 & 0.615 & 0.623 & 0.56 & 0.593 & 0.624 \\
4 & -1 & -1 & -1 & 0.622 & 0.626 & 0.549 & 0.598 & 0.621 \\
5 & 0 & 0 & 0 & 0.62 & 0.633 & 0.559 & 0.593 & 0.62 \\
6 & 1 & -1 & -1 & 0.615 & 0.632 & 0.645 & 0.586 & 0.617 \\
7 & 0 & 0 & 0 & 0.62 & 0.633 & 0.567 & 0.593 & 0.62 \\
8 & -1 & 1 & -1 & 0.624 & 0.629 & 0.629 & 0.594 & 0.633 \\
9 & 1 & 1 & -1 & 0.624 & 0.632 & 0.565 & 0.601 & 0.618 \\
10 & 0 & 0 & 0 & 0.62 & 0.633 & 0.567 & 0.593 & 0.62 \\
11 & 1 & -1 & 1 & 0.62 & 0.622 & 0.546 & 0.577 & 0.577 \\
12 & 0 & 0 & 0 & 0.62 & 0.633 & 0.567 & 0.593 & 0.62 \\
13 & 0 & 0 & 0 & 0.62 & 0.633 & 0.567 & 0.593 & 0.62 \\
14 & 0 & 0 & 2 & 0.614 & 0.627 & 0.544 & 0.586 & 0.62 \\
15 & 2 & 0 & 0 & 0.625 & 0.627 & 0.561 & 0.595 & 0.616 \\
16 & 0 & 0 & 0 & 0.62 & 0.633 & 0.567 & 0.593 & 0.62 \\
17 & 0 & 0 & -2 & 0.632 & 0.645 & 0.587 & 0.605 & 0.629 \\
18 & -1 & 1 & 1 & 0.616 & 0.622 & 0.543 & 0.576 & 0.607 \\
19 & 0 & 2 & 0 & 0.615 & 0.633 & 0.573 & 0.591 & 0.627 \\
20 & -2 & 0 & 0 & 0.617 & 0.618 & 0.645 & 0.583 & 0.606 \\
\hline & & & & & & & &
\end{tabular}

The deviation is the lowest to a tune of $0.0266 \mathrm{~mm}$ and highest to an extent of $0.0621 \mathrm{~mm}$ at different sample sizes. The deviations observed at the points are taken up and analysed. It is found that about $77.98 \%$ of points of the total population are within $\pm 1 \%$ standard deviation which indicates that moderately larger deviations occurred sporadically at less number of places of the chosen component. The minimum deviation is almost constant irrespective of the sample size; however, the maximum deviation has reduced constantly with the increase of sample size while the curvature deviation is minimum with $60 \%$ sample size and maximum with $40 \%$ sample size. It is observed that curvature deviation has exhibited an erratic variation in the chosen samples. The deviation is maximum in each of the samples when the parameter triangle count is at its lowest level of $20 \%$ while the curvature deviation in the lowest ebb when the parameter smoothing level is equal to 6. The data of the results have been subjected to ANOVA and the coefficients are evaluated for their importance at 5\% level of significance. A typical ANOVA table for deviation is given in Table 4. 
Table 4. ANOVA table for deviation (95\% confidence level 5\% level of significance)

\begin{tabular}{cccccccc}
\hline S No & Model & Coefficient & Estimate & SS & DOF & MS & F \\
\hline 1 & - & $\mathrm{b}_{0}$ & 0.042 & $1.80 \mathrm{E}-004$ & 9 & $2.01 \mathrm{E}-005$ & 13.6 \\
2 & $\mathrm{~A}$ & $\mathrm{~b}_{1}$ & $-3.33 \mathrm{E}-004$ & $7.56 \mathrm{E}-008$ & 1 & $7.56 \mathrm{E}-008$ & 0.05 \\
3 & $\mathrm{~B}$ & $\mathrm{~b}_{2}$ & $-3.17 \mathrm{E}-004$ & $9.16 \mathrm{E}-005$ & 1 & $9.16 \mathrm{E}-005$ & 62.3 \\
4 & $\mathrm{C}$ & $\mathrm{b}_{3}$ & $+1.50 \mathrm{E}-003$ & $4.00 \mathrm{E}-005$ & 1 & $4.0 \mathrm{E}-005$ & 27.2 \\
5 & $\mathrm{AB}$ & $\mathrm{b}_{4}$ & $+4.68 \mathrm{E}-006$ & $3.12 \mathrm{E}-008$ & 1 & $3.12 \mathrm{E}-008$ & 0.02 \\
6 & $\mathrm{AC}$ & $\mathrm{b}_{5}$ & $-3.43 \mathrm{E}-005$ & $2.81 \mathrm{E}-007$ & 1 & $2.81 \mathrm{E}-007$ & 0.19 \\
7 & $\mathrm{BC}$ & $\mathrm{b}_{6}$ & $-1.60 \mathrm{E}-005$ & $9.03 \mathrm{E}-006$ & 1 & $9.03 \mathrm{E}-006$ & 6.14 \\
8 & $\mathrm{~A}^{2}$ & $\mathrm{~b}_{7}$ & $+4.43 \mathrm{E}-005$ & $6.87 \mathrm{E}-008$ & 1 & $6.87 \mathrm{E}-008$ & 0.04 \\
9 & $\mathrm{~B}^{2}$ & $\mathrm{~b}_{8}$ & $+1.86 \mathrm{E}-006$ & $3.41 \mathrm{E}-005$ & 1 & $3.41 \mathrm{E}-005$ & 23.21 \\
10 & $\mathrm{C}^{2}$ & $\mathrm{~b}_{9}$ & $+8.37 \mathrm{E}-005$ & $9.89 \mathrm{E}-006$ & 1 & $9.89 \mathrm{E}-006$ & 6.73 \\
11 & Residual & & & $1.47 \mathrm{E}-005$ & 10 & $1.47 \mathrm{E}-006$ & \\
\hline
\end{tabular}

The final regression equations for deviation and curvature deviation in their actual parameter values are given in Table 5 and Table 6 respectively. Both responses are predominantly governed by the parameter smoothing levels and to a lesser extent by the parameter triangle count. These parameters also have interaction effect on the responses while the other parameter noise reduction level neither has the individual nor the interaction effect significantly on the deviation and curvature deviation, hence got eliminated from the regression equations.

Table 5. Regression equation for deviation

\begin{tabular}{ccl}
\hline S.No & $\begin{array}{c}\text { (\% of } \\
\text { population }) \\
\text { Sample Size }\end{array}$ & \multicolumn{1}{c}{ Regression equation in actual values } \\
& 20 & $\begin{array}{l}0.042892-3.17670 \mathrm{E}-004 * \mathrm{~B}+1.60937 \mathrm{E}-005^{*} \mathrm{~B} * \mathrm{C}+1.86861 \mathrm{E}- \\
006 * \mathrm{~B}^{2}\end{array}$ \\
& 40 & $\begin{array}{l}0.033258-1022202 \mathrm{E}-004 * \mathrm{C}-6.64063 \mathrm{E}-006 * \mathrm{~B} * \mathrm{C}+7.27983 \mathrm{E}-007 \\
\mathrm{~B}^{2}+3.92045 \mathrm{E}-005 * \mathrm{C}^{2}\end{array}$ \\
2 & 60 & $0.30318-6.46023 \mathrm{E}-005 * \mathrm{~B}+2.13068 \mathrm{E} 004 * \mathrm{C}+3.58665 \mathrm{E}-007 * \mathrm{C}^{2}$ \\
3 & 80 & $0.028677-4.85085 \mathrm{E}-005 * \mathrm{~B}+1.50565 \mathrm{E}-004 * \mathrm{C}+2.96165 \mathrm{E}-007 * \mathrm{C}^{2}$ \\
4 & 100 & $0.028263-3.25852 \mathrm{E}-005 * \mathrm{~B}+1.72585 \mathrm{E}-007 * \mathrm{~B}^{2}$ \\
5 & &
\end{tabular}

Table 6. Regression equation for curvature deviation

\begin{tabular}{|c|c|c|}
\hline S.No & $\begin{array}{c}\text { (\% of } \\
\text { population) } \\
\text { Sample Size }\end{array}$ & Regression equation in actual values in actual values \\
\hline 1 & 20 & $\begin{array}{l}0.61809-7.98295 \mathrm{E}-004 * \mathrm{C}-1.32812 \mathrm{E}-005 * \mathrm{~B} * \mathrm{C}-6.81818 \mathrm{E}- \\
007 * \mathrm{~B} 2\end{array}$ \\
\hline 2 & 40 & $\begin{array}{l}0.62529+4.51723 \mathrm{E}-003 * \mathrm{~A}+1.63472 \mathrm{E}-004 * \mathrm{~B}-1.25646 \mathrm{E}-003 * \mathrm{C}- \\
7.66315 \mathrm{E}-004 * \mathrm{~A} 2-1.00625 \mathrm{E}-006 * \mathrm{~B} 2\end{array}$ \\
\hline 3 & 60 & $0.56843-3.82601 \mathrm{E}-003 * \mathrm{C}$ \\
\hline 4 & 80 & $0.59011+9.97469 \mathrm{E}-004 * \mathrm{C}$ \\
\hline 5 & 100 & $0.62784-2.08215 \mathrm{E}-003 * \mathrm{C}$ \\
\hline
\end{tabular}


The developed predictive regression equations are manipulated using contours and response surfaces, which will help in the selection of parameters for optimizing the responses. The contour plot and surface plots for the parameters triangle count and smoothing levels against the responses deviation and curvature deviation are illustrated in Figure 3 and Figure 4 respectively. These plots are drawn keeping the noise reduction held constant.

The contour plots have shown that the deviation has increased with the increase of smoothing level irrespective of the sample size chosen (Figure 3). The surface plot illustrates the largest deviation of $0.05 \mathrm{~mm}$ at highest smoothing levels and lowest triangle count for $20 \%$ sample size. Similarly, the deviation is lowest to a tune of $0.01 \mathrm{~mm}$ when the smoothing levels are 6 and triangle count is about $80 \%$ in the entire population undertaken for study.
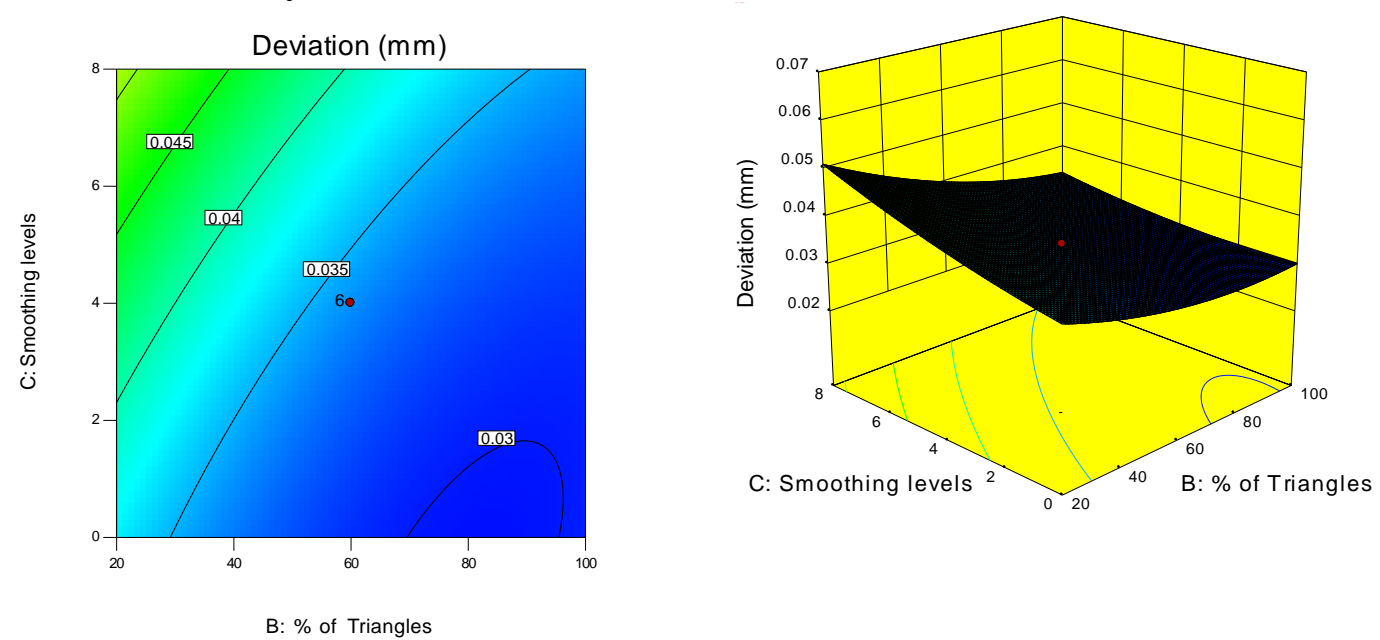

\section{$20 \%$ sampling}


$40 \%$ sampling 

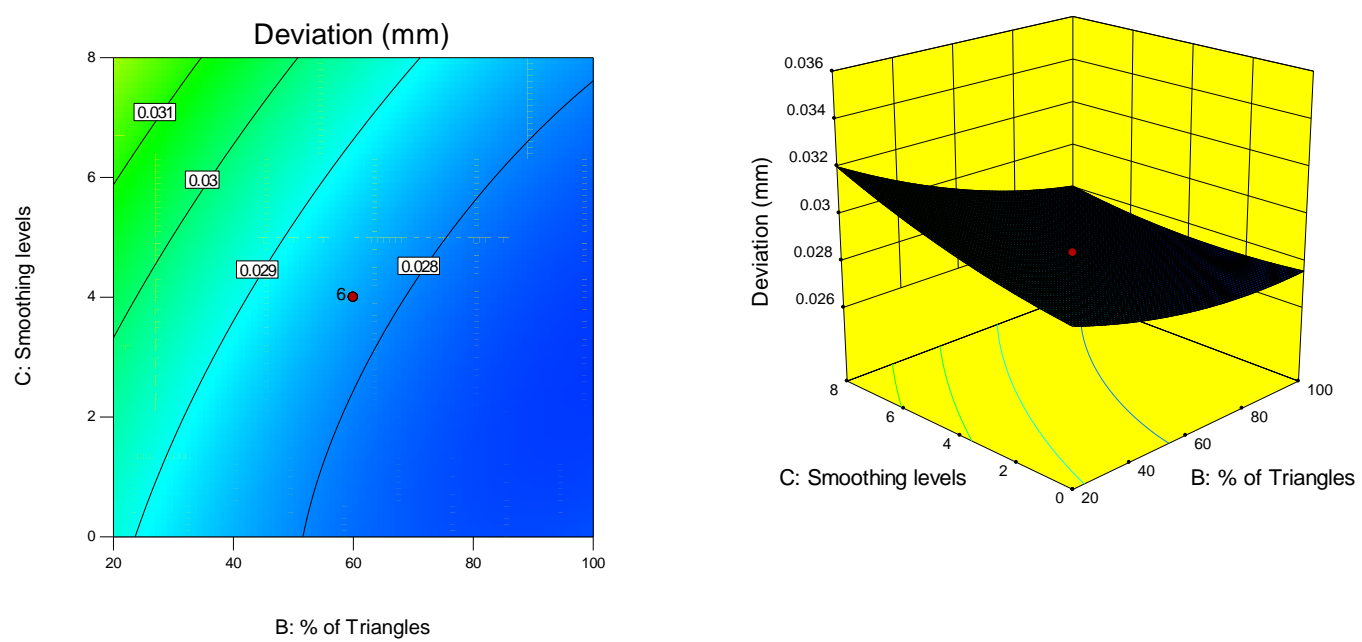

$60 \%$ sampling
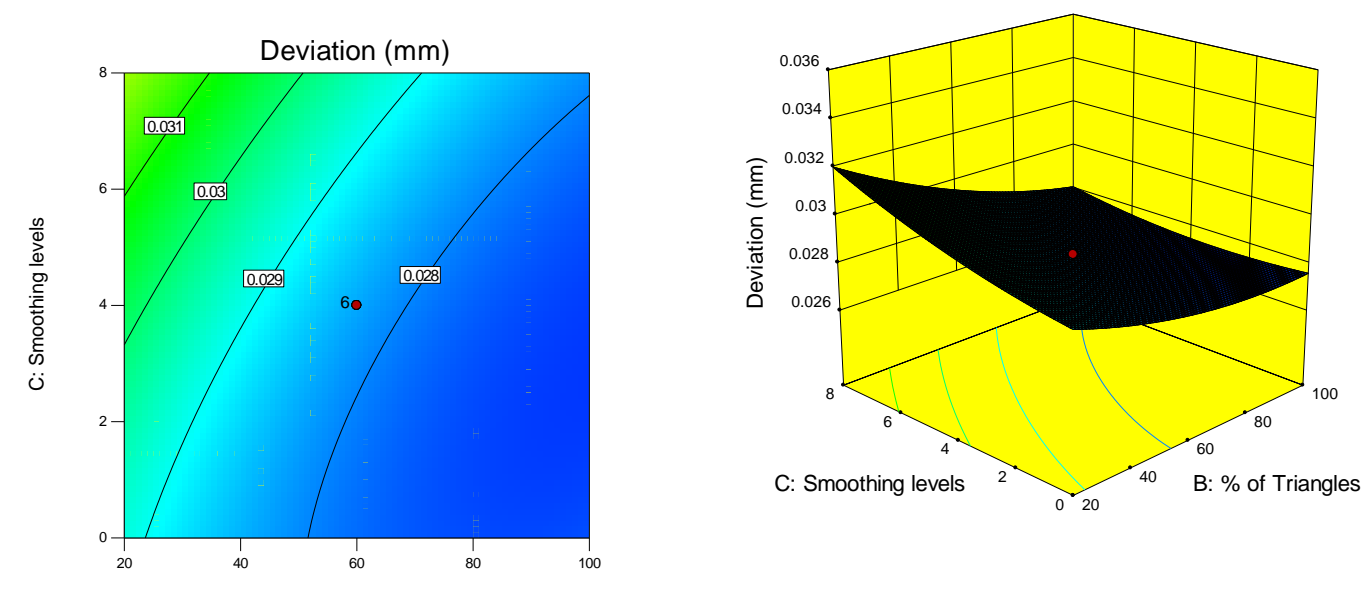

B: \% of Triangles

$80 \%$ sampling
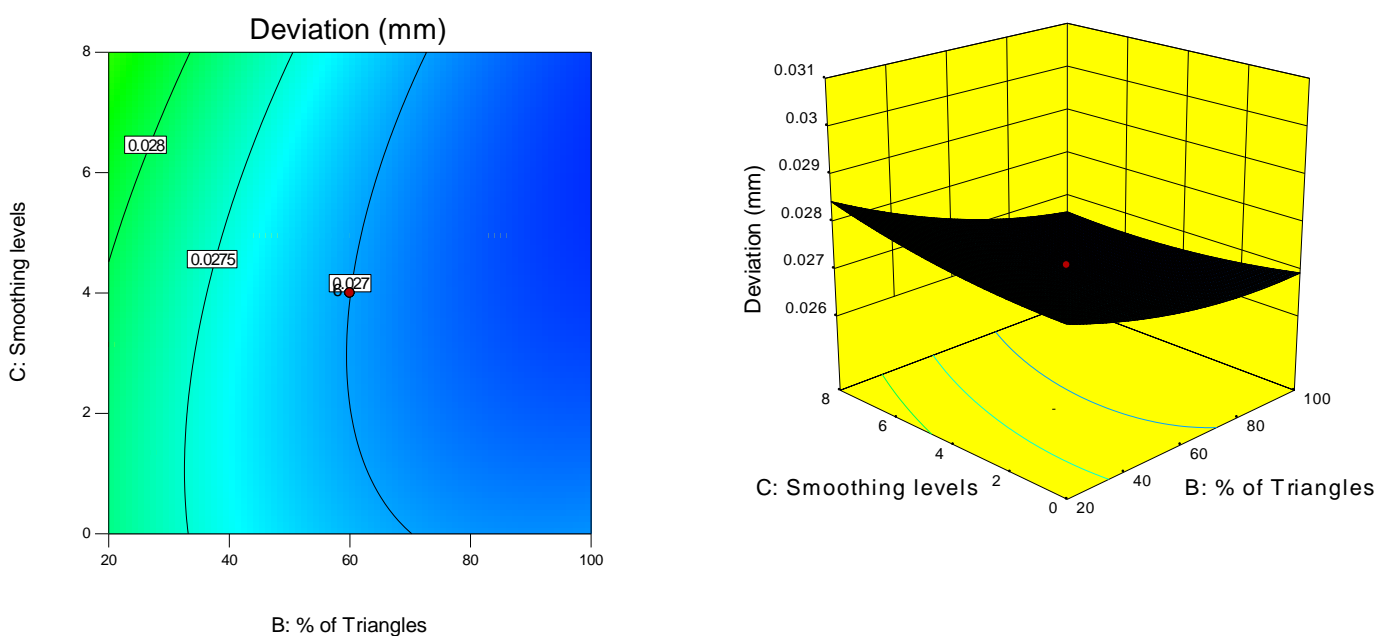

$100 \%$ sampling

Figure 3. Contour graphs and surface plots for deviation 

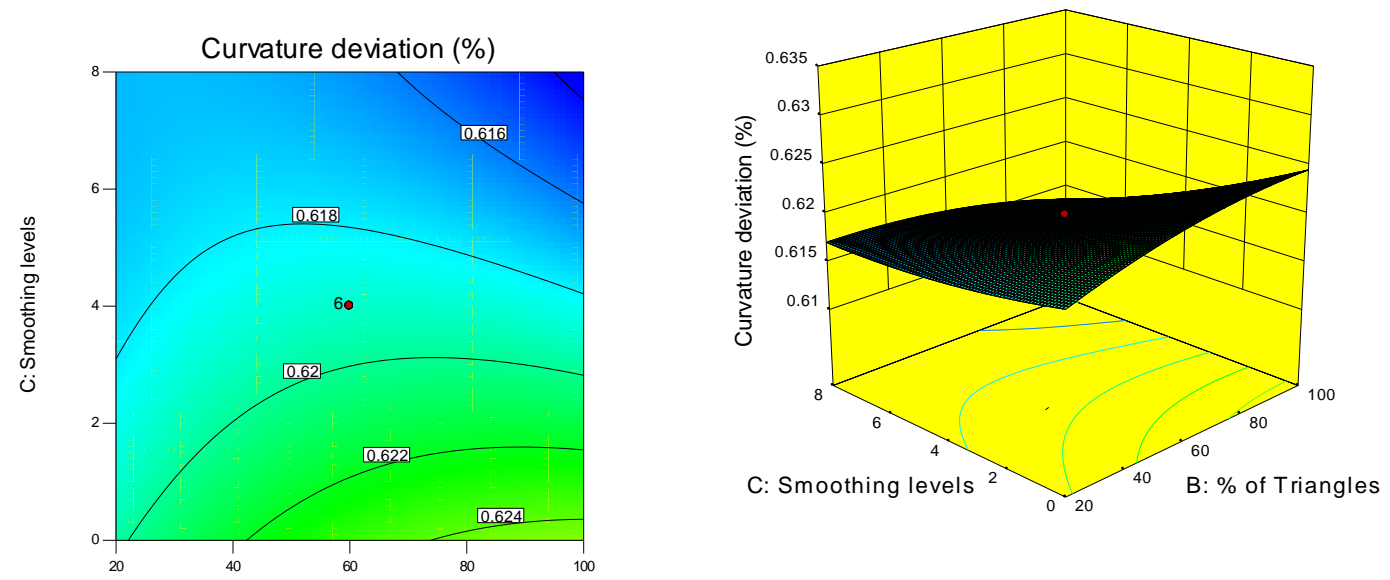

B: $\%$ of Triangles

$20 \%$ sampling
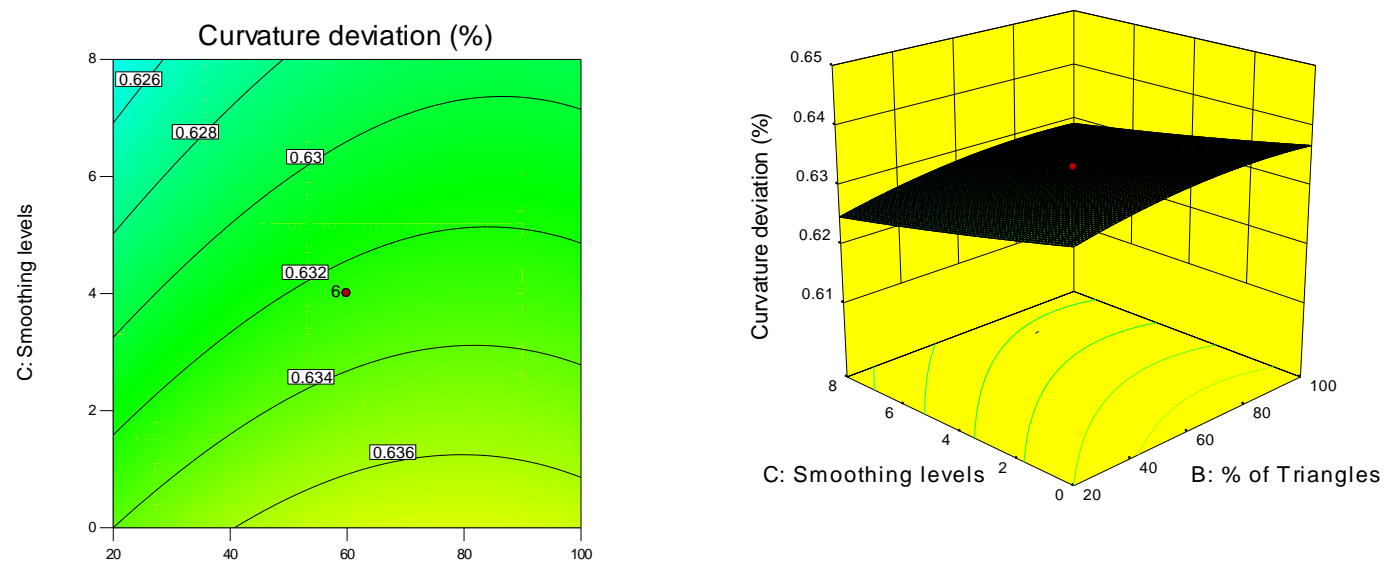

B: \% of Triangles

$40 \%$ sampling
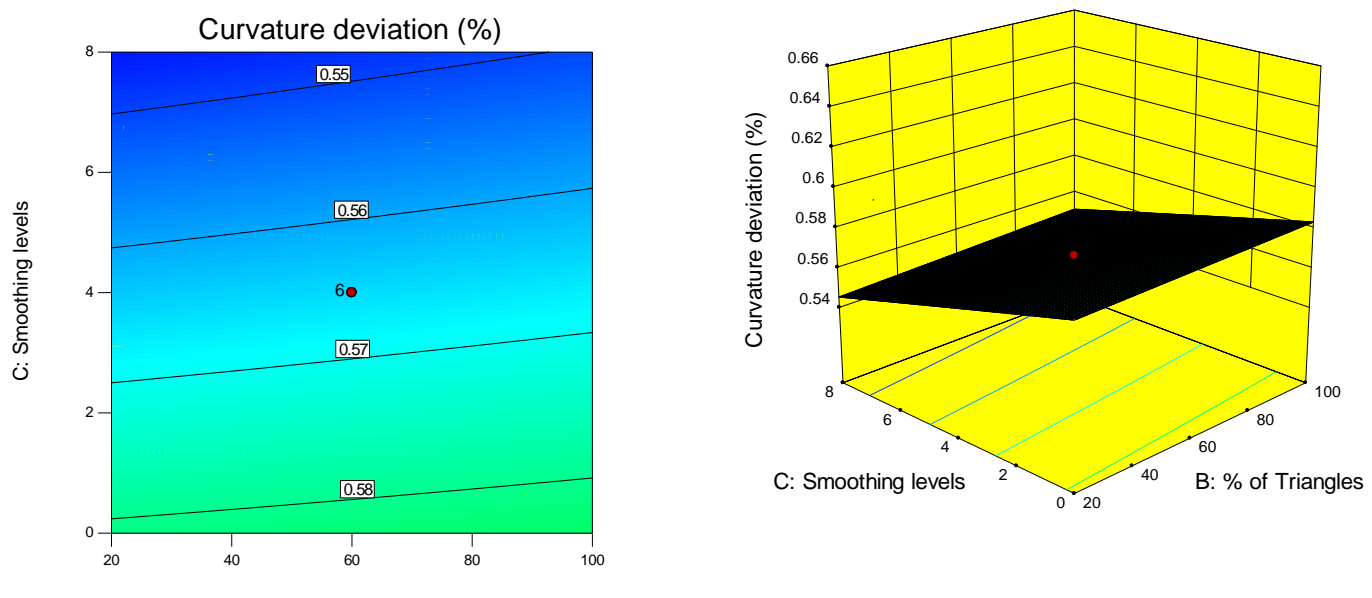

B: $\%$ of Triangles

$60 \%$ sampling 

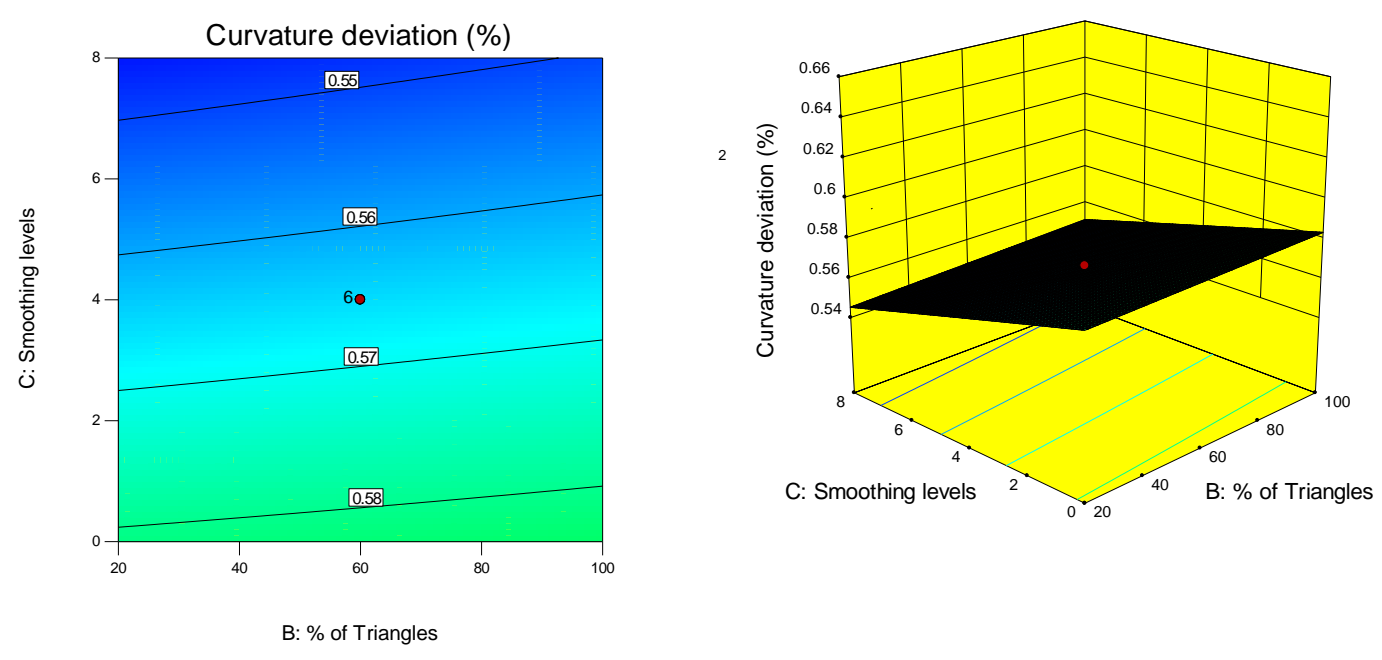

$80 \%$ sampling
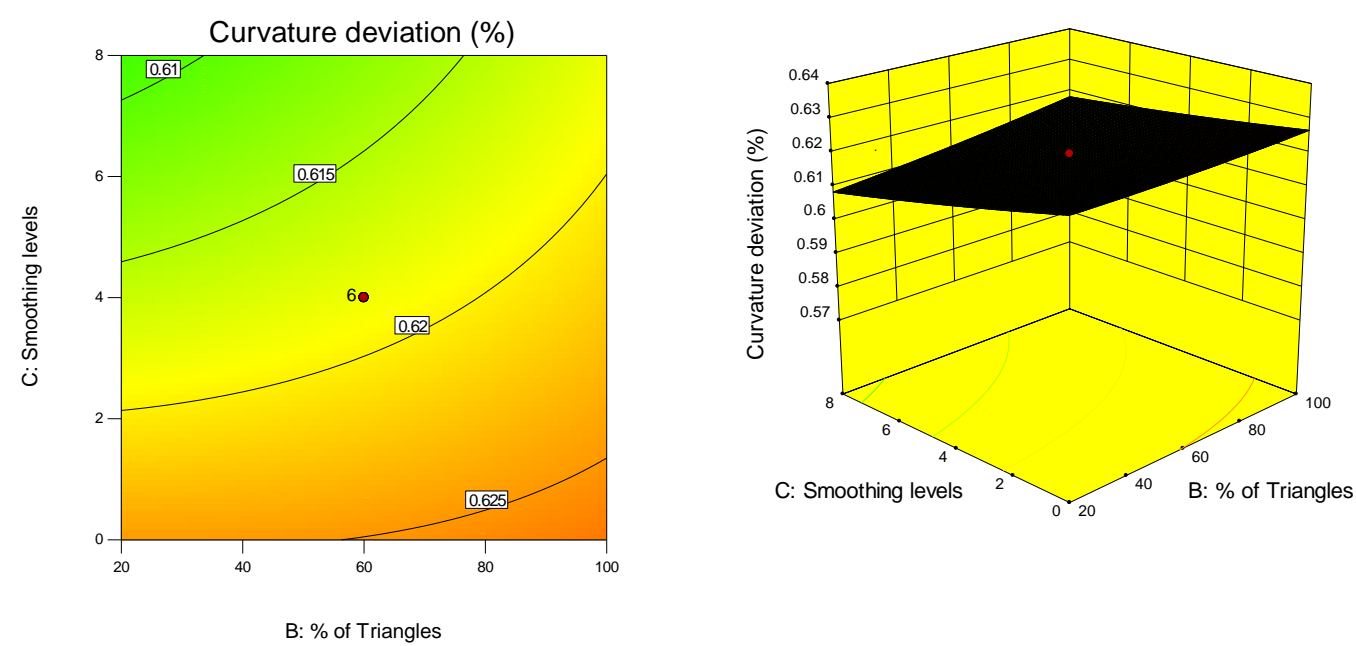

\section{$100 \%$ sampling}

Figure 4. Contour graphs and surface plots for curvature deviation

The curvature deviation is about $64.5 \%$ and is the highest when the sample size selected for analysis is $40 \%$ of the population while it is minimum at $58.7 \%$ when the sample size has increased to $60 \%$ of the population. Even though the difference in deviation from $58.7 \%$ to $64.5 \%$ is moderately significant, the increase in sample size leads to more computer memory consumption and consequent increase in processing time. The magnitude of curvature deviation has reduced with the decrease of smoothing levels and with the increase of triangle count (Figure 4). With lower sample sizes the curvature deviation has exhibited upward trend and get diverted towards lower side with the increase of triangle count, however, the trend has been reversed with increase of sample sizes. The surface plot has shown that the curvature deviation is the lowest of $0.54(54 \%)$ at lowest triangle count and highest smoothing levels (Figure 4). 


\section{CONCLUSIONS}

- Noise reduction has less influence on the deviation and curvature deviation of the reverse engineered model.

- $\quad$ The deviation gets reduced with lower smoothing levels and higher triangle count. The deviation between the reverse engineered model and CAD model is in the range 0.0266 to $0.0621 \mathrm{~mm}$.

- Similar trend is observed for curvature deviation. The curvature deviation is in the range $54.3 \%$ to $64.5 \%$ at various sample sizes of the population.

- The sample size in the reverse engineered model also has significant effect. The deviation is the lowest when $100 \%$ of the sample size i.e. complete population is taken while the curvature deviation is minimum with $60 \%$ of the sample size.

- The application of reverse engineering model in the product design of classified products where the original drawings are scarcely available can be readily taken up with the quantum of lower number of differences as resulted in the current investigation.

\section{ACKNOWLEDGEMENTS}

The authors express their sense of gratitude to Epigraph Technologies, Hyderabad for the support extended. The authors also thank the Director and Correspondent of Vidya Jyothi Institute of Technology, Aziz Nagar, Hyderabad, India, for the continuous encouragement.

\section{REFERENCES}

[1] Rekoff M, On Reverse Engineering, IEEE Transactions on Systems Man and Cybernetics. 1985; 3: 244-52.

[2] Chikofsky E, Cross J Reverse Engineering and Design Recovery: A Taxonomy. IEEE Software. 1990; 7: 13- 17.

[3] Otto K, Wood K, Product Evolution: A reverse Engineering and Redesign Methodology. Research in Product Development. 1998; 10: 226-43.

[4] El-Hayek N, Nouira H, Anwer N, Damak M, Gibaru O Reconstruction of Freeform Surfaces for Metrology. Journal of Physics: Conference Series. 2014; 483: 012003/1-12.

[5] Carlos Relvas, António Ramos, António Completo, and José António Simões, Accuracy Control of Complex Surfaces in Reverse Engineering, International Journal of Precision Engineering and Manufacturing. 2011; 12: 1035-1042.

[6] Shuo-Jen L, Dar-Huan C. A laser sensor with multiple detectors for freeform surface digitization. Int J Adv Man Tech. 2006; 31:474-82.

[7] Korosec M, Duhovnik J, Vukasinovic N. Process modeling of non-contact reverse engineering process. In: Proceedings of the $7^{\text {th }}$ WSEAS international conference on signal processing, computational geometry and artificial vision (ISCGAV'07, Vouliagmeni, Athens, Greece: WSEAS Press. 2007; 87-96.

[8] Xi F, Liu H, Feng Y. Error Compensation for three-dimensional Line Laser scanning data. Int J Adv Manuf Technol. 2001; 18:211-16.

[9] Shiou FJ, Ali YC. Development of a non-contact multi-axis reverse engineering measurement system for small complex objects. In: 7th international symposium 
on measurement technology and intelligent instruments. J Phys: Conf Ser. 2005; 13:178-81.

[10] Marjan Korosec, Joze Duhovnik, Nikola Vukasinovic, Identification and optimization of key process parameters in noncontact laser scanning for reverse engineering, Computer-Aided Design. 2010; 42; 744-48.

[11] Nabil Anwer and Luc Mathieu, From reverse engineering to shape engineering in mechanical design CIRP Annals - Manufacturing Technology. 2016; 65:165-68.

[12] G. Sreeram Reddy, Manzoor Hussian and V. V.Satyanarayana, Experimental Investigation To Optimize Parameters of Reverse Engineering Technology For Reconstructing Freeform Surfaces. International Journal of Mechanical Engineering and Technology. 2016; 7: 165-74.

[13] A.M.A. Al-Ahmari, Javed Aalam, Optimizing parameters of freeform surface reconstruction using CMM, Measurement. 2015; 64: 17-28.

[14] Montgomery, C, Design and Analysis of experiments, 4th ed. Wiley, New York, 1997.

[15] Cochran WG and COKGM, "Experiments Design" Charles Etutrile Company, Japan, 1968.

[16] Pravin R. Parate and Ravindra B. Yarasu, Application of Taguchi and ANOVA in Optimization of Process Parameters of Lapping Operation for Cast Iron, Journal of Mechanical Engineering and Sciences (JMES).2013;4:479-487.

[17] Md. Ashikur Rahman Khan, M.M. Rahman, K. Kadirgama, M.A. Maleque and M. Ishak, Prediction of Surface Roughness of Ti-6Al-4V in Electrical Discharge Machining: A Regression Model , Journal of Mechanical Engineering and Sciences (JMES).2011;1:16-24.

[18] V.V. Satyanarayana, A. Chennakesava Reddy, and S. Sundararajan, Reduction of Casting Porosity in the LostWax Process Choosing Right Coating Materials by Response Surface Criteria, CEMILAC Conference, Ministry of Defence, India, 20-21 August, 1999; 110-14.

[19] T. Gatzke, C. Grimm, M. Garland and S. Zelinka, curvature maps for local shape comparison, International conference on Shape Modelling and applications, SMI05. 2005; 244-53.

[20] G. Sreeram Reddy, Manzoor Hussain, J. Jagadesh Kumar, V.V. Satyanarayana, A Novel Approach To Compute Gaussain Curvature Deviation Using Reverse Engineering Technique, International Journal of Mechanical and Production Engineering Research \& Development. 2016; 6: 17-24. 